\title{
Territórios amazônicos de reforma agrária e de conservação da natureza
}

\author{
Amazonian territories of agrarian
}

reform and nature conservation

Neide Estercil

Kátia Helena Serafina Cruz Schweickardt"

Resumo: $\bigcirc$ artigo discute a relação entre os pequenos produtores e o Estado, na Amazônia brasileira, por meio de algumas situações que se configuraram desde meados do século $X X$, em diferentes conjunturas e em função de diferentes políticas governamentais de ordenação territorial. Recupera o fato de que, nos anos 1970 e 1980, o Estado negou sistematicamente as formas tradicionais de apropriação do espaço adotadas pelas comunidades de pequenos produtores e homogeneizou a forma de domínio sobre a terra através do conceito legal de propriedade privada, visando à integração da região à economia nacional por meio das grandes empresas. Reflete sobre os efeitos da democratização do país e da difusão das políticas ambientais, nas décadas seguintes, quando os movimentos sociais de pequenos produtores se aliaram aos ambientalistas e se fortaleceram politicamente, e os projetos de desenvolvimento sustentável passaram a disputar espaço como os projetos desenvolvimentistas. Por meio do processo de criação de duas unidades de proteção ambiental, que envolveu pequenos produtores e agências governamentais de reforma agrária e meio ambiente, no curso médio do rio Juruá, no estado do Amazonas, pergunta-se em que medida foram alteradas, nas últimas décadas, as relações entre o Estado e os pequenos produtores na região.

Palavras-chave: Sujeitos sociais emergentes. Campesinato. Estado. Território. Rio Juruá. Amazônia.

Abstract: The article discuss the relationship between small producers and the State in the Brazilian Amazon, through situations that started in the middle of $X X$ th century, in different contexts and with different state policies for territorial management. It recovers the fact that in the 1970's and 1980's, the State systematically condemned traditional forms of space appropriation common to collectivities of small producers and standardized the form of control over the land through the legal concept of private property, aiming at the integration of the region to national economy through large corporations. It also reflects on the effects of the process of re-democratization of the country and the diffusion of environmental policies in the following decades, when social movements of small producers made alliances with environmentalists, became politically more influential, and the projects of sustainable development began to compete with other development projects. Taking as an example the process of creation of two environmental protected areas in the Jurua River, in the Amazonas state, that involved small producers and agencies of the federal government related to Agrarian Reform and Environment, we argue about the extent to which the relationship between the State and the small producers of the region have change substantially due to this context.

Keywords: Emerging social subjects. Peasantry. State. Territory. Jurua River. Amazon.

\footnotetext{
Universidade Federal do Rio de Janeiro. Rio de Janeiro, Rio de Janeiro, Brasil (esterci@uol.com.br).

Instituto Nacional de Colonização e Reforma Agrária. Manaus, Amazonas, Brasil (katia.helena@uol.com.br).
}

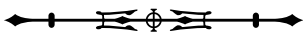




\section{A (RE)PRODUÇÃO DO TERRITÓRIO NA AMAZÔNIA}

Territórios, como referências espaciais de relações de identidade e solidariedade, nacionais e locais, pareciam estar perdendo relevância como elementos da prática social e como objetos de pesquisa. Entretanto, vários autores têm registrado o ressurgimento da inscrição espacial das coletividades, de modo que noções de território têm suscitado discussões políticas, e motivado pesquisas e indagações teóricas.

Em março de 2006, realizou-se, no Brasil, a Conferência Internacional sobre Reforma Agrária e Desenvolvimento Rural (CIRADR). Paralelamente, transcorreu o foro "Terra, Território e Dignidade". A conferência, segundo Maria Emília Lisboa Pacheco (20052006, p. 100-105), adotou uma visão por ela avaliada como muito restrita de reforma agrária, ao "falar apenas de terra sem incluir o conceito de direitos territoriais"(p. 101). Acrescentou a autora:

\begin{abstract}
(...) é preciso conjugar na análise da questão agrária o sentido de território, que é muito mais amplo. (...) Falar de território significa falar de modos de vida. $\bigcirc$ território é condição de existência, de sobrevivência física para as populações que compartilham da mesma origem e elaboram uma unidade. É espaço de produção, de relação com a natureza (matas e florestas, rios, animais), e um lugar também de simbologia, incluindo o sentido sagrado da terra para várias populações (p. 3).
\end{abstract}

De fato, no Brasil, especialmente na Amazônia, a evocação do conceito de território, seja como instrumento de políticas públicas, acionado por planejadores e legisladores, seja como objeto de reivindicação de direitos por parte de povos e grupos sociais, tem sido tão frequente que a região se tornou um complexo mosaico de muitos territórios regidos por diferentes estatutos, muitas vezes em disputa ou mesmo sobrepostos. No livro "Terras Indígenas e Unidades de Conservação da Natureza - o desafio das sobreposições" (Ricardo, 2004), publicado pelo Instituto Socioambiental, vários pesquisadores descrevem e discutem diversos casos de disputa e de sobreposição, sendo uma referência importante para compreender o que está ocorrendo.

Outro exemplo do ressurgimento das preocupações em torno da noção de território, desta vez fora do Brasil, é a coletânea publicada pelo Institut National de la Recherche Agronomique (INRA), na França, sob o título "Territoires en questions: pratiques des lieux, usages d'un mot" (Alphandery e Bergues, 2004). Nesta publicação, a noção de território é examinada por vários autores, sob diversos ângulos e em diversas situações, mas os organizadores partem da noção muito simples de território como "uma forma particular de demarcação do espaço, mais ou menos institucionalizada" (p. 5). Distinguem, por um lado, os territórios produzidos para fins de ação pública e de representação política, visando à administração local; e, por outro lado, os territórios construídos de forma mais difusa e menos institucionalizada, como manifestações das diversas formas de apropriação do espaço que os indivíduos e os grupos sociais produzem e transformam no curso das relações que estabelecem entre si e com o seu meio. São aqueles espaços, dizem os autores, que as coletividades humanas organizam e modelam por meio de suas práticas materiais e simbólicas. Veremos que essa noção e distinção são muito úteis para pensar as situações que aqui focalizamos.

Na Amazônia brasileira, vários pesquisadores identificaram e descreveram as particularidades dessas práticas imprimidas ao espaço por povos indígenas, mas também por pequenos produtores do tipo camponês. Com sua organização econômica distinta da empresa capitalista, baseada na unidade familiar de produção e consumo, sua autonomia relativa face à sociedade em que se insere e sua capacidade de sobreviver a vários sistemas e situações socioeconômicas, conforme estudos realizados no Brasil e em outras partes do mundo por inúmeros autores (Foster, 1967; Wolf, 1977, 2003; Queiroz, 1976; Heredia e Garcia Jr., 1971; Esterci, 1987). As particularidades das formas camponesas de apropriação do espaço aparecem, principalmente, nas áreas em que, em função da eventual 
inexistência de outros pretendentes e da frágil presença de agências estatais, esses pequenos produtores foram criando suas formas próprias de segmentação, domínio, apropriação e atribuição de significados aos espaços ocupados (Esterci, 1987, 2009; Almeida, 1995, 2008; Martins, 1993).

Se nas décadas anteriores essas particularidades não foram sequer consideradas pelos órgãos governamentais (Little, 2002), em momentos mais recentes observam-se os efeitos das mudanças havidas nas relações de poder entre o Estado e os pequenos produtores, como novos sujeitos políticos. Num cenário de redemocratização das instituições e de fortalecimento das organizações populares, a difusão das preocupações ambientalistas se fez sentir tanto na legislação quanto nos estatutos e nas práticas das agências estatais, em especial do Instituto Nacional de Colonização e Reforma Agrária (INCRA) e do Instituto Brasileiro do Meio Ambiente e dos Recursos Naturais Renováveis (IBAMA), abrindo, de fato, alternativas para os novos sujeitos políticos, embora se possa discutir até que ponto essas novas possibilidades representam ganhos reais de liberdade e autonomia, minimizando, pelo menos, o poder tutelar do Estado sobre as coletividades camponesas residentes. Com base em pesquisa de campo, documental e bibliográfica, e a partir de informações obtidas por meio de entrevistas, argumentamos que pequenos produtores, em algumas situações, têm podido se valer, inclusive, dos instrumentos de ação do próprio Estado para defender seus espaços, não apenas como lotes familiares, segundo o Estatuto da Terra, mas como territórios.

\section{DESENVOLVIMENTISMO, COLONIZAÇÃO E ASSENTAMENTOS RURAIS - CONVERTENDO A NATUREZA EM ÁREAS DE EXPLORAÇÃO PARA O MERCADO}

Para efeitos de distinção entre as diversas conjunturas para o campesinato amazônico desde meados do século $X X$, podemos tomar como objeto, primeiramente, a situação que se configurou nos anos 1970, no estado do Mato Grosso, por onde começou a intervenção sistemática do Estado no processo de territorialização regional.
Essa intervenção teve início por meio das políticas de incentivo à atividade agropecuária de grande escala e dos programas de colonização que transferiram pequenos produtores de outras regiões para as chamadas 'áreas de fronteira'. Posteriormente, por meio de projetos de assentamento de pequenos produtores que, embora não envolvessem deslocamentos entre regiões, implicavam recortar antigos territórios, também distribuídos como lotes familiares.

A marca dessas políticas governamentais é que eram orientadas para o uso intensivo da terra e dos recursos naturais. Tanto os empreendimentos agropecuários, cujos projetos passavam pela Superintendência do Desenvolvimento da Amazônia (SUDAM), quanto os projetos convencionais de assentamento de pequenos produtores, que constituíram a meta fundamental das políticas executadas pelo INCRA na Amazônia, desde a década de 1970, foram, até o final dos anos 1990, desenhados a partir do modelo de uso intensivo dos recursos naturais, sobretudo florestas, solo e água. A ideia subjacente a esta estratégia de territorialização, que já vinha sendo posta em prática desde os anos 1950, e que passou a ser sistematicamente implantada a partir dos governos militares, era a transformação de uma região - considerada como demograficamente vazia e economicamente desintegrada do resto do país - e de seus espaços de natureza - percebidos como improdutivos - em áreas de exploração voltadas para o mercado. $\bigcirc$ estado do Amazonas, por um tempo, ficou relativamente a salvo dessas políticas territoriais, pois ali foram incentivadas as atividades industrial e pesqueira.

Para realizar esse projeto de integração da Amazônia à economia nacional era preciso homogeneizar as formas de domínio sobre a terra e os recursos naturais, ignorando ou superando as formas construídas localmente, e à revelia do próprio Estado, ao longo de décadas ou séculos. $O$ choque entre os agentes do projeto desenvolvimentista e os habitantes das localidades da fronteira foi, ao mesmo tempo, revelando a lógica das formas locais de uso e de 
domínio sobre a terra e os recursos naturais. De fato, a Amazônia, ainda hoje, expõe, no conjunto das calhas dos seus rios, uma diversidade de modos de vida relacionados não apenas ao uso e à posse das áreas de terra firme, mas também ao uso e às formas de domínio sobre as áreas de várzea e sobre as águas, nas quais seus habitantes praticam, invariavelmente, a pesca conjugada de diferentes maneiras a outras atividades econômicas, de modo que não só na terra firme, mas também nas áreas de várzea e sobre as águas, eles constroem seus caminhos, suas casas e escolas flutuantes (Benatti, 2005; Lima, 2005).

A noção atualmente tão criticada de 'vazio demográfico' fazia parte do arcabouço conceitual dos planejadores de então, levando-os a negar todo este complexo de interações do homem com seu meio, fosse dando as terras como desabitadas, fosse impondo as noções do código legal às formas de ocupação já existentes. Classificando-as como formas precárias de domínio, como posse, por exemplo, facultavam às agências do Estado a liberdade de recortá-las conforme seus critérios. As 'agências de desenvolvimento' se punham, assim, a reordenar o território com vistas a abrir caminho para o desenvolvimento, tal como concebido pelos planejadores dos governos militares (Schweickardt, 2001).

A hegemonia desenvolvimentista, que ganhou corpo após a Segunda Guerra Mundial, significou a consolidação da crença no domínio da natureza, sendo o desenvolvimento a "chave modernizadora universal" que levaria as sociedades tidas como primitivas ou atrasadas à civilização (Gonçalves, 1996)1. Como argumenta Davis (1978), em "As Vítimas do Milagre", fazendo o Brasil crescer de 10 a $11 \%$ ao ano, tais políticas tinham ampla aprovação por parte de planejadores no âmbito internacional. Muito poucos questionavam os danos sociais e ambientais que elas implicavam.

A matriz desenvolvimentista das agências estatais não lhes permitia reconhecer os significados de 'posse' (Martins,
1993, 1994) nem de 'propriedade' (Esterci, 2009), construídos com base em outros parâmetros e identificados pelas pesquisas realizadas à época entre camponeses amazônicos. Para essas agências, tratava-se de abrir espaço à lógica e aos empreendimentos capitalistas, de modo que o choque com as lógicas existentes explodiu em inúmeros conflitos.

As disputas e alegações das partes envolvidas em um desses conflitos, ocorrido no nordeste do atual estado do Mato Grosso, são um bom exemplo da especificidade da organização camponesa no espaço. Mesmo a palavra não sendo utilizada, estava em jogo a noção de território como um espaço sobre o qual a coletividade exercia algum tipo de controle, regulando informalmente a entrada e a fixação de eventuais 'chegantes' (Esterci, 2009).

Sobre o espaço territorial, no caso observado, havia várias formas de domínio. Uma delas, a 'propriedade', abarcava o espaço ocupado pela casa de uma família, a roça, o sítio, as capoeiras e também os espaços ainda não trabalhados, mas tidos como reserva para cultivo de novas roças anuais. Os limites eram definidos por meio das regras costumeiras, tendo em vista as necessidades, o tamanho da família e a disponibilidade de braços para o trabalho. Se os sinais materiais pareciam vagos, os arranjos sociais eram bem definidos e implicavam uma clara delimitação dos direitos de cada grupo familiar sobre o espaço disponível.

Oterritório, contudo, incluía também as áreas de uso comum, como pastagens naturais, fontes de água, florestas para retirada de madeira para o reparo da casa e das cercas, para a coleta de frutas silvestres e de plantas medicinais. Nele estavam incluídos os caminhos que ligavam umas casas às outras, os espaços rurais à sede do povoado. Mas o Estatuto da Terra, invocado pelos camponeses e seus aliados das equipes locais da Igreja Católica na defesa de seus direitos, facultou-lhes apenas a garantia de acesso a lotes familiares.

De fato, como a maioria das autarquias federais, sobretudo as originadas da ditadura militar, o INCRA, até

Segundo Carlos Walter Gonçalves (1996), des-envolvimento significa etimologicamente não envolvimento, separação da natureza. Histórica e socialmente, significou o domínio da natureza e dos homens semiotizados como naturais. 
o final da década de 1990, teve o poder de definição de suas políticas concentrado na administração central, em Brasília, que ignorou os particularismos regionais e se impôs aos planejamentos estaduais e municipais. Tratava-se de preparar as condições para a empresa capitalista.

A partir dos anos 1980, no entanto, já era evidente o fracasso dos grandes projetos agropecuários, base do modelo desenvolvimentista na região. $\bigcirc$ Estado, então, retirou o suporte ou incentivo à agropecuária regional, o que veio ao encontro das preocupações ambientais com a região, que começavam a se difundir no país no final da década.

\section{O ADVENTO DE OUTROS CRITÉRIOS COMO INSTRUMENTOS DE TERRITORIALIZAÇÃO}

Nos anos 1990, vieram somar-se aos projetos de assentamento de pequenos produtores familiares e ao reconhecimento de terras indígenas, o reconhecimento de terras remanescentes de quilombos (Almeida, 2008) e a criação das unidades de conservação (UCs) (Brito, 2000), que multiplicariam os territórios instituídos pelo Estado. Difundiram-se as preocupações ambientais e, ao contrário do que se passara nas décadas anteriores, na nova conjuntura de ampliação dos espaços democráticos e de crescimento dos movimentos sociais, ganhou força a orientação para manter as populações humanas residentes nas áreas ambientalmente protegidas. Não sendo essas áreas subdivididas em lotes, preservaram-se, assim, as antigas fronteiras territoriais.

A criação de muitos desses espaços territoriais tem sido objeto de reivindicação de grupos sociais residentes. Regidos por estatutos fixados na legislação, esses espaços territoriais guardam as marcas impressas pelos habitantes, garantem a eles acesso e controle sobre os recursos existentes, funcionam como base de sua organização local e como proteção de seus modos de vida. Ao reconhecer e legitimar essas pretensões, no entanto, os agentes públicos negociam e dão novas formas à intervenção do Estado, por meio das quais consolidam o seu poder tutelar, do que falaremos mais adiante.
Dois novos modelos de territórios ambientalmente protegidos foram formulados nesse contexto e se tornaram categorias importantes do Sistema Nacional de Unidades de Conservação (SNUC), aprovado em 2000. São eles os modelos de Reserva de Desenvolvimento Sustentável (RDS) e de Reserva Extrativista (RESEX), que se constituíram como instrumentos de políticas públicas e, muitas vezes, como objetos de reivindicação de grupos sociais locais.

$O$ modelo RESEX foi elaborado por meio do diálogo entre pesquisadores, principalmente das ciências sociais, líderes sindicais seringueiros, aliados e assessores, politicamente engajados em movimentos sociais do estado do Acre, muitos deles ligados a organizações político-partidárias de esquerda. Emergindo da luta dos seringueiros contra a usurpação de seus territórios, o modelo RESEX foi, muitas vezes, designado pelos próprios envolvidos como a reforma agrária dos seringueiros, e denunciado por opositores, na arena ambiental, como uma espécie de política social de formato não muito adequado aos objetivos da conservação (Almeida, 1992, 1995, 2004; Allegretti, 2002; Franco, 2008). A ideia de reserva foi inspirada nas reservas indígenas, vizinhas às terras reivindicadas pelos seringueiros, sendo a orientação de não dividir a terra em lotes familiares, segundo pesquisadores, uma opção dos próprios líderes seringueiros, que ideologicamente assim se contrapunham à ideia de propriedade privada, ao mesmo tempo em que mantinham a integridade territorial do seringal e se protegiam contra eventuais vendas de lotes familiares. As duas primeiras Reservas Extrativistas - Chico Mendes e Alto Juruá, ambas no estado do Acre - tiveram grande repercussão e mobilizaram muitos recursos humanos e materiais.

$\bigcirc$ modelo RDS foi elaborado por pesquisadores das áreas humanas e biológicas, ligados ao movimento e a organizações ambientalistas que já desenvolviam trabalhos na várzea do Solimões e testemunhavam a degradação do ecossistema resultante da super exploração dos recursos. A demanda de criação de uma área legalmente protegida 
acabou sendo atendida pelo governo do estado do Amazonas, que decretou a criação de uma Estação Ecológica abarcando uma extensão muito maior do que a originalmente solicitada pelos pesquisadores, que incluía dezenas de assentamentos de pequenos produtores. A criação de grandes unidades de conservação não habitadas já havia sido criticada (Ayres, 1993). Os pesquisadores formularam o modelo RDS, que foi incorporado à legislação do estado em 1996, sendo a RDS Mamirauá a primeira a ser criada e implantada. Os pesquisadores aliaram-se a equipes locais da Igreja Católica, que, preocupados com a ameaça de esgotamento dos recursos pesqueiros, já vinham desenvolvendo um trabalho ligado às comunidades ribeirinhas, construindo mecanismos e espaços de participação e propostas de melhoria das condições de vida dos moradores. Em 2000, o modelo foi incorporado como categoria do SNUC (Lima, 1997, 2004; Reis, 2005; Queiroz, 2005; Moura, 2007).

Ao discutir as dimensões sócio-antropológicas da produção e (re)produção de territórios na região, uma situação observada no curso médio do rio Juruá, no estado do Amazonas, permite colocar em perspectiva a distinção entre os dois modelos aqui referidos e indagar sobre as mudanças ocorridas na relação entre o campesinato amazônico e o Estado, na conjuntura das duas últimas décadas. Veremos como esses pequenos produtores têm se apropriado dos instrumentos de ação política dos planejadores, para seus próprios fins e em função de suas estratégias de garantia da terra, dos recursos e dos seus modos de vida.

Na conjuntura pós anos 1990, contexto de maior relevância atribuída à problemática ambiental, foram criadas em certo ponto do curso do rio, na sua margem esquerda, uma RESEX e, na sua margem direita, uma RDS. Aparentemente, nada justificaria a criação de dois modelos diferentes de unidade de conservação, já que não há descontinuidade significativa entre as duas margens do rio, seja em termos de fatores ecológicos, seja em termos da história ou das características sociais dos moradores. $\bigcirc$ que, então, teria levado à criação e ao estabelecimento de duas áreas protegidas com estatutos distintos?

\section{A AMBIENTALIZAÇÃO DOS PROCESSOS DE TERRITORIALIZAÇÃO NA AMAZÔNIA A PARTIR DO ESTADO DO AMAZONAS}

No Amazonas, as primeiras tentativas de institucionalização da questão ambiental se deram no final da década de 1980, e se fizeram por meio das Coordenadorias de Ecologia e de Recursos Naturais do Centro de Desenvolvimento, Pesquisa e Tecnologia do Estado do Amazonas (CODEAMA). Em 1989, foi criado o Instituto de Desenvolvimento dos Recursos Naturais e Proteção Ambiental do Estado do Amazonas (IMA), que, todavia, ainda não se dispôs a priorizar as questões ambientais, voltando suas ações, sobretudo, para as questões fundiárias do estado.

A questão ambiental passou a ter um direcionamento mais efetivo, em termos das políticas públicas estaduais, em 1996, com a criação do Instituto de Proteção Ambiental do Amazonas (IPAAM), que, com o apoio da cooperação internacional, passou a traçar estratégias para a política de gestão ambiental do estado. No mesmo ano da criação do IPAAM, foi criada, no médio rio Solimões, a primeira Unidade de Conservação de Uso Sustentável, a RDS Mamirauá.

A implantação do novo modelo, no contexto das mudanças pelas quais passava a orientação ambientalista mundial, inaugurou, no estado do Amazonas, uma orientação contrária aos modelos muito restritivos de unidades de conservação, que não admitiam a permanência de moradores e usuários.

AAmazônia começava a se transformar num "imenso laboratório de políticas e projetos que, de uma forma ou de outra, tentam compatibilizar a presença dos habitantes com algum tipo de medida visando à conservação dos ecossistemas em que eles vivem" (Esterci, 2002, p. 51). A implementação desses projetos e políticas levou à demarcação de uns espaços, à redefinição e reclassificação de outros, assim como à reclassificação dos próprios segmentos sociais afetados. Partilhando do conceito de Leite Lopes (2004, 2006), poderíamos caracterizar este processo como a "ambientalização" da gestão territorial na Amazônia. Mais que a definição de um fenômeno 
moderno, o conceito diz respeito, entre outras coisas, ao modo como os diversos atores (trabalhadores, empresários) e, sobretudo, o Estado e suas agências passam a utilizar a questão ambiental como repertório de argumentos em prol de seus interesses e reivindicações.

Tal processo implica transformações nas diversas relações sociais, entre as quais Leite Lopes $(2004,2006)$ destaca as transformações no Estado e no comportamento das pessoas. Agências públicas, como o INCRA/AM, o IBAMA/AM e a Secretaria de Estado de Meio Ambiente e Desenvolvimento Sustentável do Amazonas (SDS), vêm refazendo suas estratégias de produção de territórios, ao mesmo tempo em que a gestão agrária do território no estado vai também, aos poucos, se 'ambientalizando'.

\section{INTERFACES DAS PROBLEMÁTICAS AGRÁRIA E AMBIENTAL}

No contexto da redemocratização do país e das mudanças no nível do Estado que deram origem ao que ficou conhecido como a Nova República, foi criado o Ministério da Reforma Agrária e do Desenvolvimento (MIRAD). Operouse, então, uma mudança na política fundiária, como resultado de pressão do movimento de pequenos produtores, no caso o Movimento dos Trabalhadores Sem Terra (MST): a ênfase desta política deixou de ser a colonização e as metas do governo federal, até então contabilizadas em números de títulos definitivos expedidos aos posseiros, por meio de regularização fundiária, passaram a incorporar outros indicadores. Embora a atuação deste movimento fosse mais expressiva em outros estados e regiões, sua pressão acabou por repercutir nas superintendências regionais do INCRA na Amazônia, sobretudo nos estados do Amazonas, Amapá e Roraima. A pressão operava em dois sentidos: que os indicadores passassem a ser o volume de terras desapropriadas para fins de reforma agrária e o montante do número de famílias assentadas em Projetos de Assentamento (PA); e que as famílias de sem terra fossem alocadas nos seus municípios ou regiões de origem, em virtude dos efeitos trágicos dos grandes deslocamentos induzidos pelas medidas governamentais anteriores (Medeiros, 1989; Tavares-dosSantos e Ruscheinsky, 2000). As pressões do MST foram uma pá de cal na política de colonização.

A partir de 1985, as metas do governo federal já não estavam centradas tão enfaticamente na titulação de grandes áreas de terras públicas e em grandes projetos de colonização. O foco da política agrária havia se deslocado para a criação e implantação de PA. Tais projetos eram implantados segundo a metodologia estabelecida na administração central, em Brasília, tendo por base a demarcação de lotes individuais de terra, segundo planejamento feito em gabinete e sem a mínima preocupação com a participação dos atuais ou dos futuros moradores. A efetivação de um assentamento começava pelo corte raso da vegetação em parte do lote. Este corte era considerado a primeira benfeitoria, o que funcionava como comprovação de trabalho investido nos lotes e respaldava o direito do titular da terra, a partir da vistoria dos técnicos do INCRA, em visita aos assentamentos. Os lotes encontrados ainda cobertos com a vegetação nativa eram considerados abandonados e os relatórios técnicos informavam a necessidade de serem retomados e destinados a novos pretendentes - outros trabalhadores despossuídos de terra, cadastrados nos bancos de dados oficiais.

Quando o debate acerca das questões ambientais tornou-se proeminente, os programas relacionados à questão agrária e à territorialização passaram a ser objeto de outro tipo de questionamento, desta vez por parte das organizações ambientalistas e dos Ministérios Públicos Federais que, sobretudo no estado do Amazonas, passaram a exigir o licenciamento ambiental dos Projetos de Assentamento, conforme determinava a legislação vigente à época. Os questionamentos tinham como base de sustentação a inadequação dos projetos de reforma agrária às condições ecológicas e sociais da Amazônia. Alguns procuradores federais questionavam o INCRA acerca da relação entre os 'ganhos sociais reais' desses projetos e os 'danos ambientais' por eles causados.

Ao ser assim interpelada pelo Ministério Público Federal, em 1997, a Superintendência do INCRA no 
estado do Amazonas começou um processo de revisão dos procedimentos adotados na execução das políticas desde a implantação do órgão na região, na década de 1970. A tarefa de levantamento do passivo ambiental dos projetos mais antigos e a adoção de medidas mitigadoras dos impactos já causados demandavam tempo e recursos para um redirecionamento dos Projetos de Assentamento em curso. Além do alargamento do prazo para tais procedimentos, o INCRA solicitava tratamento diferenciado para os Projetos de Assentamento, que eram arrolados junto a todos os demais empreendimentos comerciais e empresariais causadores de impacto ambiental ${ }^{2}$. Isto obrigava o INCRA a solicitar licenças ambientais para os assentamentos seguindo os mesmos cronogramas e submetido aos mesmos custos despendidos pelos empreendimentos comerciais e empresariais. $O$ INCRA/AM argumentava que Projetos de Assentamento tinham caráter de política social e dispunham de uma dotação orçamentária limitada para serem implantados.

Desses debates resultaram uma legislação de licenciamento específica para os projetos de reforma agrária ${ }^{3}$ e o início de uma relação mais sistêmica entre os diferentes órgãos encarregados da gestão de territórios no estado do Amazonas, ou seja, entre INCRA, IBAMA e SDS.

Embora tenha se estabelecido uma sintonia maior entre as ações dos diferentes órgãos no estado do Amazonas, muitos desafios ainda se colocavam. $\bigcirc$ principal deles era o de como regionalizar a política nacional de reforma agrária, facultando o acesso aos recursos do Programa Nacional de Reforma Agrária, não apenas aos pequenos produtores assentados pelo INCRA, mas também aos demais pequenos produtores, como os ribeirinhos, os produtores extrativistas, entre os quais os seringueiros, as quebradeiras de coco, os coletores de castanha, e os pescadores residentes ou não em unidades de conservação de uso sustentável. Todos deveriam ser reconhecidos como legítimos beneficiários da 'reforma agrária amazônica'.

\section{EXPERIÊNCIAS DE REFORMA AGRÁRIA AMAZÔNICA}

\section{AS TERRITORIALIDADES PROPOSTAS PELOS SUJEITOS SOCIAIS EMERGENTES}

O reconhecimento de várias categorias sociais como beneficiárias das ações de reforma agrária provocou um deslocamento na política pública de caráter nacional, conferindo-lhe uma feição mais amazônica. Esse deslocamento não se deu por iniciativa dos gestores públicos somente, mas sim em função da emergência dos seringueiros, extrativistas e ribeirinhos da Amazônia enquanto coletividades cujas identidades políticas se objetivaram em movimentos sociais com características e reivindicações muito próprias. Esses sujeitos sociais emergentes se distinguiam das demais organizações de trabalhadores rurais no Brasil, uma vez que sua forma de organização social e econômica no espaço era incompatível com o modo de territorialização que lhes impunham os planejadores oficiais.

A emergência dessas identidades coletivas, por meio de uma série de movimentos sociais, como o dos seringueiros, das quebradeiras de coco babaçu, dos atingidos por barragens, dos quilombolas e de tantos outros, levou ao que Almeida (2008) entende como uma desconstrução da concepção 'naturalizada da natureza', colocando-a como uma representação em um campo de disputas.

Antes profetizados como em vias de extinção, os diferentes sujeitos sociais amazônicos passaram, de fato, de uma existência percebida como atomizada para uma existência coletiva objetivada em movimentos sociais, de modo que, recuperando Weber (1992) ao analisar as

Conforme Resolução do Conselho Nacional do Meio Ambiente (CONAMA) No. 237, de 1997

3 Resolução CONAMA No. 289/2001 e, mais recentemente, a Resolução CONAMA No. 387/2006, que revogou a anterior.

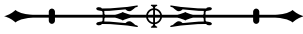


"comunidades étnicas", se pode compreender a vontade de agir politicamente como uma das realidades escondidas por trás de conceitos como 'tribo' e 'povo'. Desse modo, emergem identidades coletivas como unidades de mobilização, aglutinando interesses específicos de grupos sociais não necessariamente homogêneos, mas que se agrupam a partir de critérios político-organizativos.

Esses novos sujeitos coletivos, ao estabelecerem novas alianças entre si e com outros diferentes atores sociais, como Igrejas, organizações não governamentais, movimentos ambientalistas, pesquisadores, agências internacionais e políticos, convertem a territorialização imposta no que Almeida (2008) denominou de "territorialidades específicas", assim nomeando as delimitações físicas de determinadas unidades sociais que compõem territórios etnicamente configurados. Essas territorialidades resultam de diferentes processos sociais de territorialização (Oliveira Filho, 1999) e delimitam dinamicamente terras de pertencimento coletivo que convergem para um território cujo reconhecimento está expresso na legislação vigente, mas que ainda é objeto de inúmeras disputas, como aquelas que se referem à demarcação e à defesa de terras indígenas, ao reconhecimento de territórios quilombolas, ou as que ocorrem entre ribeirinhos, extrativistas e camponeses da Amazônia e os agentes do agronegócio.

As mobilizações e reivindicações desses sujeitos políticos emergentes se assemelham em muitos aspectos às mobilizações dos povos indígenas que levaram à decretação das várias terras indígenas na Amazônia e, como elas, possuem uma importante dimensão ambiental e geopolítica (Oliveira Filho, 1999), como expressam as ações e propostas de seringueiros e extrativistas (Almeida, 1992, 2004; Cunha e Almeida, 2002; Allegretti, 2002; Franco, 2008).

O território, antes espaço físico arbitrariamente recortado à revelia das práticas, dos significados atribuídos ao espaço e das necessidades de uso dos povos e grupos sociais locais, como acontecia nos Projetos de Assentamento convencionais, converte-se, assim, em espaço de diálogo entre diferentes agentes públicos e os sujeitos sociais politicamente constituídos na região, que passam a reivindicar, a partir de seus movimentos sociais, o reconhecimento de territorialidades específicas. Tais territorialidades sugerem outra cartografia. Outros parâmetros são agora envolvidos nos recortes do espaço, contrapondo-se, como propõe Oliveira Filho (1999), à territorialização antes imposta pelo Estado, e convertendose em "processo de territorialização", a partir dos sujeitos sociais emergentes e socialmente organizados, e quebrando, assim, o monopólio dos planejadores oficiais sobre a definição legítima do território. A peculiaridade do "processo de territorialização", conforme conceituado por Oliveira Filho (1999), é que os objetos político-administrativos ("comunidades indígenas", "moradores de Unidades de Conservação", "seringueiros" etc.) transformam-se em uma ou em várias coletividades organizadas, que reestruturam até mesmo suas formas culturais.

Sob este novo prisma, os agentes públicos dos órgãos governamentais ambientais, oficialmente gestores das áreas protegidas (IBAMA, no nível federal, e SDS, no nível do estado) ou vinculados às questões agrárias (INCRA), são desafiados a repensar a territorialização pela qual sempre pautaram seus procedimentos. Por meio do protagonismo assumido pelos novos movimentos de pequenos produtores e extrativistas, inicia-se outro modo de se constituírem políticas públicas territoriais na região e estas, ao se efetivarem, vão ressignificando a Amazônia no contexto nacional e internacional.

\section{A PRIMEIRA RESEX, AFINAL, INSTITUCIONALMENTE RECONHECIDA COMO 'PROJETO DE REFORMA AGRÁRIA'}

A primeira grande demonstração de aproximação dos órgãos fundiários, gestores de território, com relação às populações tradicionais, na Amazônia, se deu por meio do reconhecimento, por parte do INCRA, dos moradores da Reserva Extrativista Médio Juruá, no município de Carauari, Amazonas, como beneficiários da política nacional de 
reforma agrária. Esta iniciativa inovadora desafiou as normas internas do INCRA nacional, especialmente em relação ao Programa de Crédito 'Apoio à Instalação' e 'Habitação', uma vez que implicava repasse de recursos da reforma agrária para essas populações. Até então, o INCRA só fornecia crédito na modalidade Apoio para alimentação e fomento da atividade produtiva com a compra de implementos para o início da atividade, e auxílio na modalidade Habitação para a construção de casas, para assentados recém-chegados à terra. Estender tais benefícios a grupos já residentes na localidade, às vezes, há décadas; viabilizar a aquisição de alimentos para moradores das beiras de rios, distantes muitas vezes do centro comercial urbano; financiar implementos para atividades que não são estritamente agrícolas, como a pesca e o extrativismo, gerou muita perplexidade, especialmente em virtude do modo como a direção nacional do INCRA percebia as populações da Amazônia. A novidade levou a significativas mudanças no modo como o órgão passou a conceber a política de gestão territorial que vinha sendo executada no estado do Amazonas.

A ideia começou a ser debatida entre técnicos do INCRA e do Centro Nacional de Desenvolvimento Sustentado das Populações Tradicionais (CNPT) ${ }^{4}$, no Amazonas, em 1999, e posteriormente foi assumida pelos superintendentes dos dois órgãos como uma possibilidade real de levar os benefícios do programa de reforma agrária àqueles que eram, de fato, os demandantes desta política no estado, onde extrativistas e ribeirinhos são a maioria da população rural, aos quais, no entanto, as políticas públicas do governo federal quase não chegavam até então (Schweickardt, 2010).

Firmado o primeiro convênio entre os superintendentes regionais dos dois órgãos, os moradores da RESEX Médio Juruá foram 'acomodados' no Sistema de Informações de Projetos de Reforma Agrária (SIPRA), banco de dados do INCRA que registra e monitora as famílias a serem beneficiadas com recursos da reforma agrária, sendo classificados como "assentados em projetos especiais" e não como 'seringueiros' ou 'extrativistas', conforme sua auto-identificação. De fato, tais identidades ainda não eram legalmente previstas, o que impediria destinar-lhes recursos do INCRA. Feita a 'acomodação' através da recategorização, os residentes no território formalmente demarcado pelo IBAMA como uma RESEX, a partir da reivindicação das populações locais e dos movimentos sociais, passaram a ter acesso aos créditos da reforma agrária. Posteriormente, esta iniciativa foi estendida a outras unidades de conservação de uso sustentável, como Florestas Nacionais (FLONA) e Reservas de Desenvolvimento Sustentável (RDS), incluindo não só as unidades federais, então administradas pelo IBAMA, como também as estaduais, inaugurando, por meio da relação SDS e INCRA, um novo tipo de parceria e de diálogo entre órgãos do governo federal e do governo estadual.

\section{NO MÉDIO RIO JURUÁ - UM CASO PARA PENSAR}

O processo de ambientalização da gestão territorial, que na Amazônia aproximou INCRA/AM, IBAMA/AM e SDS, resolveu alguns conflitos interinstitucionais, mas evidenciou outros. O caso do médio rio Juruá serve para pensar questões que revelam/ocultam novas e velhas articulações entre Estado e populações locais no processo recente de produção de territórios na região.

Existe no município de Carauari (AM), à margem esquerda do rio, a RESEX do Médio Juruá, e na margem direita, a RDS Uacari. Como não parecem existir diferenças significativas entre as paisagens dos dois lados do rio, a primeira pergunta que esta intervenção territorial suscita é: por que não foi criada uma mesma categoria legal de UC, abrangendo as duas margens do rio, como, aliás, haviam solicitado os moradores?

\footnotetext{
4 Setor do então IBAMA, atualmente vinculado ao Instituto Chico Mendes de Biodiversidade (ICMBio), anteriormente responsável pela criação, implantação e monitoramento das unidades de conservação de uso sustentável.
} 
RESEX e RDS são unidades de conservação com estatutos diferentes, estando, no médio Juruá, a primeira subordinada ao governo federal e a segunda ao governo estadual. A RESEX do Médio Juruá foi criada em 1997 e a RDS Uacari, em 2005. Por terem estatutos diferentes, as UCs chamam atenção primeiro porque não se percebe diferença significativa entre as paisagens das duas margens, ou entre as pessoas que habitam uma e outra margem do rio, havendo entre elas, inclusive, laços de parentesco rituais e consanguíneos, relações de compadrio, muitas delas tendo trajetórias semelhantes, partilhando uma história social comum, e sendo membros da mesma organização - a Associação de Produtores Rurais de Carauari (ASPROC). Mas, este arranjo territorial suscita ainda mais questões pelo fato de serem, RESEX e RDS, modalidades diferentes de UC, uma estadual, outra federal; por serem modelos formulados por atores sociais diferenciados, a partir de histórias sociais diferentes e apoiadas por orientações políticas e articulações sociais também distintas.

Na verdade, esta situação do médio Juruá sugere uma indiferenciação dos dois modelos, que seria impensável em termos dos projetos originais. $\bigcirc$ contexto de formulação dos modelos e de implantação das unidades pioneiras de cada uma dessas categorias, no início dos anos 1990, era muito diferente. E não só em termos do montante de recursos materiais, mas também do tipo de atores mobilizados para sua implantação. É o que sugerem a pesquisa realizada por Thais Danton Coelho (2009) e as observações feitas por Ronis da Silveira ao comparar, por exemplo, as condições de implantação da RDS Piagaçu-Purus, nos anos 2000, com as condições de implantação da RDS Mamirauás. Além dos recursos e do pessoal envolvido, ele se refere também ao trabalho das equipes da Igreja Católica junto às comunidades, base importante no processo de implantação da RDS Mamirauá, no médio Solimões, e que praticamente inexistia no Purus por ocasião das primeiras tentativas de implantar a RDS Piagaçu-Purus.

A própria adesão político-ideológica inicial a um e outro modelo, por parte dos pequenos produtores e de seus aliados, tendeu a se diluir, como demonstra o caso aqui analisado. No médio Juruá, se por questões legais uma área contígua não pôde ser criada, por que a segunda UC foi criada em uma modalidade diferente e proposta por outra instância governamental? Que processos teriam levado a esta peculiar 'di-visão' de territórios? O que é possível compreender sobre critérios e processos de territorialização recentes a partir deste caso?

O território é um espaço marcado pelas atividades sociais daqueles que o habitam e agem sobre ele. $\bigcirc$ espaço social se re-traduz no espaço físico (Bourdieu, 2004). As descontinuidades são disputadas e promovidas pelos diversos atores, segundo o seu poder de classificar. As diferentes posições sociais que ocupam os atores e as variações que ocorrem no tempo fazem com que diferentes classificações sejam impostas aos mesmos objetos, no caso, segmentos do espaço feitos territórios. São classificações espaciais que, como afirma Bourdieu (1998, p. 112), estão "subordinadas a funções práticas e orientadas para a produção de efeitos sociais", dando a ilusão de uma realidade objetiva que naturaliza e camufla os conflitos.

O médio Juruá foi uma importante região produtora de borracha, sobretudo nos anos que precederam a Primeira Guerra Mundial e nos anos da Segunda Guerra. O reaquecimento da economia da borracha na década de 1940 durou até os anos 1970, quando o governo brasileiro ainda tentou, por meio da criação da Superintendência do Desenvolvimento da Borracha (SUDHEVEA) e de alguns programas especiais de modernização da produção de borracha, como os Programas de Incentivo à Produção da Borracha Natural (PROBOR I, II e III), financiar os

\footnotetext{
5 Entrevista concedida às autoras pelo Dr. Ronis da Silveira, professor e pesquisador da Universidade Federal do Amazonas, em julho de
} 2009, sobre suas pesquisas na RDS Mamirauá e a tentativa de implantar a RDS do Purus. 
seringalistas e aumentar a produção do látex. Essas medidas voltaram a fortalecer alguns barracões e a reforçar também o sistema de coerção de patrões sobre os trabalhadores por meio do aviamento dos seringais. Mas, esses efeitos foram apenas temporários (Derickx, 1992; Cunha e Almeida, 2002).

Não tendo as iniciativas governamentais surtido os resultados esperados, muitos seringalistas abandonaram os seringais ou passaram a explorar simultaneamente a madeira e os recursos pesqueiros dos lagos da região, dando início à grande pressão que, nas décadas seguintes, iria se exercer sobre a principal fonte de alimentos dos seringueiros.

A Igreja Católica, em especial, por meio da Paróquia de Carauari - administrada, na década de 1980, pelo padre holandês João Dereckx - e do Movimento de Educação de Base (MEB), desempenhou, então, um papel fundamental no processo organizativo dos seringueiros e moradores da calha do médio rio Juruá. Foi o apoio que lhes permitiu resistir à nova forma de expropriação das suas condições de sobrevivência. Boa parte da memória desses tempos, assim como cópias de documentos referentes às reivindicações feitas às autoridades pedindo providências em apoio às populações indígenas e seringueiras daquela região, encontra-se no livro escrito pelo próprio padre João Dereckx por ocasião da fase preparatória da Conferência da Organização das Nações Unidas (ONU) para o Meio Ambiente e o Desenvolvimento Sustentável (ECO-92): "No coração da Amazônia - Juruá, o rio que chora" (Derickx, 1992). Anos mais tarde, o livro ganhou uma nova edição, sob o título "Reserva Extrativista, mais vida neste chão" (Derickx, 2007), que trata das mudanças havidas a partir da criação da RESEX Médio Juruá.
Aproximando-se das chamadas pastorais sociais da Igreja Católica, como a Comissão Pastoral da Terra (CPT) e o Conselho Indigenista Missionário (CIMI), o MEB empreendeu em Carauari um trabalho coordenado em parceria com aquele sacerdote, com o objetivo de fortalecer as comunidades ${ }^{6}$ já formadas no interior do município por meio do trabalho que vinha sendo desenvolvido por várias outras equipes locais da Igreja Católica no Brasil, desde a década de 1970. Assim, as famílias eram estimuladas a morar mais próximas umas das outras para facilitar o processo organizativo e a obtenção de alguns direitos sociais fundamentais, como escolas e postos de saúde, até então inexistentes naqueles 'beiradões'.

Tais iniciativas não eram bem vistas pelos patrões da região que, segundo relatórios das equipes do MEB, obrigavam o poder público, os prefeitos e vereadores dos quais eram aliados, a instalar os equipamentos sociais nos locais por eles determinados e não admitiam que seus 'trabalhadores/seringueiros' tivessem ligação com a Igreja, o MEB e o Sindicato de Trabalhadores Rurais, que nesta altura já tinham atuação expressiva na região (MEB, 2003)7.

Teve, então, início uma mudança significativa na trajetória das lutas na região. Com o fortalecimento de várias organizações locais, na década de 1990, o MEB começou a contratar agentes locais para um trabalho centrado mais na organização social e política, e não tanto no trabalho pastoral (MEB, 2003). Com o término do projeto do MEB na região do Juruá, alguns agentes vieram a ocupar cargos importantes em instâncias governamentais locais e estaduais. Foi o caso de um ex-agente do MEB eleito vereador pelo Partido dos Trabalhadores em Carauari, nomeado depois Secretário Municipal de Meio Ambiente, Sub-Secretário

\footnotetext{
6 Usamos o termo 'comunidade' conforme conceito de Gusfield (1975), como um grupo social que se constitui demarcando a sua diferença de outros grupos sociais, por pertencer a um mesmo local de moradia, mas, principalmente, por recorrer a uma identidade comum, a regras específicas de solidariedade e lealdade, cuja coesão é a sua própria razão de ser. É uma construção social, cuja característica crucial é o fato do pertencimento gerar direitos especiais que os membros da comunidade têm, e os outros não.

7 Parte dessas informações foi coletada por meio de entrevistas com antigos agentes do MEB que ainda estão em Carauari à frente de movimentos sociais, ou ocupando cargos em órgãos governamentais; outra parte foi extraída do documento "Memorial Institucional do MEB - Departamento de Carauari" (MEB, 2003).
}

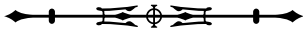


de Extrativismo do Estado do Amazonas (2003 a 2007) e ocupando atualmente o cargo de coordenador do trabalho com populações tradicionais do Centro Estadual de Unidades de Conservação (CEUC). A presença deste ex-agente de pastoral na estrutura do governo do estado explica, em parte, a criação da RDS Uacari, alguns anos depois da criação da RESEX do Médio Juruá. A RDS é a modalidade de Unidade de Conservação de Uso Sustentável preferida pelos agentes do governo do estado do Amazonas, entre outras coisas, por não ter a obrigatoriedade da desapropriação de bens privados inseridos em seu perímetro.

O início da construção de uma proposta de territorialidade específica na calha do médio rio Juruá deuse a partir de uma experiência de comercialização, apoiada pelo MEB local, com certo número de famílias de algumas comunidades de seringueiros e pequenos agricultores, formando o embrião da Associação de Produtores Rurais de Carauari (ASPROC), que viria a ser criada oficialmente um ano e meio depois do início da experiência, tendo já a participação de um número muito maior de famílias e de comunidades (Schweickardt, 2010).

Com a criação das reservas extrativistas no Acre, abriu-se em diversas localidades da Amazônia que haviam sido importantes regiões de produção de borracha uma grande discussão sobre a importância dessas reservas para os seringueiros. $O$ MEB patrocinou encontros de seringueiros no Juruá para discutir o tema e passou a trabalhar fortemente a proposta junto às comunidades e nos encontros de formação de educadores e de lideranças.

A organização da produção via ASPROC marcou um novo momento da luta contra os patrões no rio Juruá, porque muitos deles, acuados, se puseram a tentar impedir as famílias de entrarem nas áreas de coleta de produtos, de pesca e plantio de roças. Nessas condições, e motivados pela efervescência das notícias em torno da criação de RESEX e pelos encontros promovidos pelas equipes locais da Igreja Católica, pelo Sindicato de Trabalhadores Rurais de Carauari e pela ASPROC, realizou-se no médio Juruá, em 1990, uma assembleia, na qual foi produzido um documento endereçado ao IBAMA solicitando a criação de uma RESEX na região. Vinte e duas comunidades de ambas as margens do rio assinaram o referido documento. A pressão sobre o governo se fez ao longo de sete anos, até que, em 1997. foi emitido o decreto de criação da Reserva Extrativista do Médio Juruá, que, todavia, não abrangia toda a área que as comunidades haviam proposto.

$\mathrm{Na}$ mesma assembleia, importantes alianças foram estabelecidas com o IBAMA/AM por meio do relacionamento com o superintendente regional e com as instâncias federais do órgão, através de um representante de Brasília, que, na época, era ligado ao CNPT. Na assembleia, estiveram presentes representantes do Acre, que relataram sua história e partilharam experiências.

A vitória foi considerada apenas parcial porque boa parte das comunidades havia ficado fora do perímetro, definido por critérios técnicos e políticos, não incorporando os parâmetros eleitos como prioritários pelas comunidades e organizações sociais locais. $\bigcirc$ motivo alegado pelos órgãos governamentais foi que, para algumas das áreas visadas na proposta inicial dos moradores, planos de manejo de madeira já teriam sido aprovados pelo IBAMA, órgão responsável pela criação da reserva. Então, como poderia o IBAMA, que acabara de autorizar os proprietários a executar seus planos de manejo, vir a desapropriar as áreas em questão para a criação de uma RESEX? Desse modo, a limitação da área na versão aprovada no decreto excluiu várias famílias que participaram do movimento e das discussões iniciais para a criação da RESEX. Mesmo assim, a decretação da RESEX Médio Juruá, em 1997, como a primeira no estado do Amazonas, representou um momento importante para os extrativistas/seringueiros/ agricultores, sinalizando um novo caminho para a gestão de territórios na região.

Logo após a decretação da RESEX, começou toda uma movimentação para que as comunidades da outra margem do rio fossem contempladas com a criação de 
outra RESEX. A demanda, certamente, era motivada muito mais pela preocupação imediata com a garantia de direitos sobre as terras e os seus recursos, e com a manutenção de benefícios especiais, como os créditos da reforma agrária que foram estendidos aos moradores de RESEX, do que com as questões ambientais. Passados vários anos desde a criação da RESEX de um dos lados do rio, havia-se avançado muito pouco no sentido da decretação de outra RESEX na margem oposta.

Com a experiência acumulada na luta de sete anos travada pelo movimento para a criação da primeira reserva - a RESEX Médio Juruá - e já tendo se passado seis anos desde a sua criação sem que nenhuma resposta fosse dada pelo governo federal à demanda de criação da segunda reserva, as organizações locais resolveram mudar de estratégia. Aproveitando a presença de um aliado na estrutura do governo do estado, concordaram que fosse criada, na outra margem, uma modalidade diferente de unidade ambiental - uma Reserva de Desenvolvimento Sustentável (RDS), categoria legal afeta ao estado e não ao governo federal. Foi a escolha política mais adequada, já que o governo do estado do Amazonas priorizava a criação de unidades ambientais segundo este modelo. Assim, foi criada, em 2005, a RDS Uacari, abarcando as comunidades da outra margem do rio e todas as comunidades que haviam ficado fora da área da RESEX.

Vale dizer que, até o momento, os moradores dessas áreas não tiveram suas vidas afetadas pelas classificações legais dos seus territórios, e mais: continuam sendo outras as referências a partir das quais lidam com o espaço. Elas estão relacionadas às atividades sociais que realizam: são áreas de pesca, de caça, de extração de seringa, de criação de animais, de plantio de roça, de produção de farinha; ou são fronteiras e marcas de direitos, definidos a partir de relações de parentesco e compadrio; ou, a partir de lealdades políticas, ou identidades religiosas. Esta situação evidencia a diferença entre a RDS Uacari e a RDS
Mamirauá, pioneira desta categoria, na qual a efetividade da intervenção da equipe de pesquisadores e gestores foi desde o início relevante para a vida dos moradores.

\section{REENCONTRO COM A FLORESTA: O PROCESSO DE TERRITORIALIZAÇÃO AMBIENTAL DO ESTADO DO AMAZONAS}

\section{AS MUDANÇAS NO PLANO POLÍTICO E SEUS REFLEXOS NA CONJUNTURA REGIONAL}

A partir de 2003, a conjuntura política no estado do Amazonas se modificou, em parte, como veremos, devido ao processo eleitoral que levou o Partido dos Trabalhadores à Presidência da República e, também em parte, devido ao fato de o governador eleito, da base aliada do governo federal, ter feito a opção de assumir o discurso ambiental como foco das políticas estaduais. A presença do Partido dos Trabalhadores, no nível federal, provocou o acesso de alguns líderes de movimentos sociais ou aliados seus a postos nas agências de governo ligadas a questões ambientais ou fundiárias. A opção do governador teve um impacto imediato na política de gestão territorial, na medida em que a principal secretaria de estado passou a ser a Secretaria de Meio Ambiente e Desenvolvimento Sustentável (SDS), sob a coordenação de um professor da Escola Superior de Agricultura Luiz de Queiroz (ESALQ), de São Paulo, e pesquisador de manejo sustentável de madeira. A SDS passou a empreender uma política forte voltada para a territorialização ambiental do estado, que elevou o número de unidades de conservação em 150\%, fazendo a área protegida passar de sete milhões de hectares em 2003 para 17 milhões, em julho de 2008 . Ao lançar o Programa Zona Franca Verde como um contraponto político e ideológico, e ao mesmo tempo complementar ao projeto urbano-industrial da Zona Franca de Manaus, criado ainda dentro da política integracionista do projeto desenvolvimentista dos governos militares, no final da

\footnotetext{
8 Dados fornecidos pelo coordenador do CEUC, Domingos Macedo, em entrevista realizada no dia 18/07/2008.
}

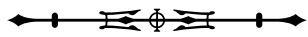


década de 1960, o governo do Amazonas inscreveu no plano discursivo a opção por uma política voltada para a valorização econômica e simbólica da floresta em pé9, em consonância com as preocupações ambientalistas mundiais, potencializada pelos efeitos do aquecimento global.

\section{DIFERENTES FACES DO SOCIOAMBIENTALISMO NA AMAZÔNIA}

Ao mesmo tempo em que defendeu a criação massiva de unidades de conservação como principal estratégia de gestão do território, o governo do estado do Amazonas tornou pública a sua opção por um modelo específico - o das Reservas de Desenvolvimento Sustentável, revelando uma posição no campo das disputas classificatórias de cunho político-social e ambiental.

As Reservas Extrativistas foram pensadas como modelo de território que, podemos dizer, se transfigurava em uma territorialidade espećfica, de acordo com a categoria proposta por Almeida (2008), porque nascia do movimento dos seringueiros, assumindo um significado coextensivo à construção da identidade política deste grupo social que se organizava e se objetivava num movimento social. $\bigcirc$ modelo tem como pressuposto a obrigatoriedade da desapropriação das terras de particulares que ficam em seu interior, o que expressa uma opção dos próprios seringueiros e sua representação, adotada na época da criação, pela reformulação da modalidade de direito à terra - não como propriedade individual, alienável, mas como direito de posse e uso comum. Uma opção prática - ninguém poderia vender a terra como lote, de modo que a base territorial dos antigos seringais seria mantida - e ideológica porque contestava a propriedade particular. Daí o modelo ter sido amplamente publicizado pelo próprio movimento como a 'reforma agrária do seringueiro' (Allegretti, 2002; Almeida, 1995, 2004).
A Reserva de Desenvolvimento Sustentável, por sua vez, foi pensada prioritariamente como um território destinado à conservação de um ecossistema importante e à produção de conhecimentos sobre os processos evolutivos desse ecossistema ainda pouco conhecido, a várzea amazônica. Tais objetivos se cumpririam em parceria e com a participação efetiva da população local, cuja qualidade de vida deveria se beneficiar com a implantação do projeto (Ayres, 1993; Lima, 1994, 2004; Queiroz, 2005; Reis, 2005).

Formulados ambos os modelos no final dos anos 1980, no contexto da redemocratização do país, da retomada das mobilizações populares, da difusão do movimento ambientalista, às vésperas da ECO-92 no Rio de Janeiro, e com as atenções internacionais voltadas para as florestas, esses modelos têm em comum a ideia de que a presença humana pode ser compatível com a conservação.

Se por algum tempo esses modelos estiveram em disputa e entre eles se dividiram as adesões dos cientistas, dos ambientalistas de diversos matizes e até das equipes religiosas atuantes na Amazônia, hoje, no médio Juruá, as populações residentes dizem nem perceber as diferenças. A despeito dos diferentes contextos locais em que foram elaborados e das questões de fundo de ordem política e ecológica em suas definições, do ponto de vista prático, da gestão política das áreas, da conservação de ecossistemas e da participação das populações residentes, os efeitos dessas diferenças parecem ter sido minimizados ao longo dos processos sociais, como se observa no caso do médio Juruá.

As duas vias para a implantação de territórios ambientais, que pareciam correr paralelas, ao serem incorporadas à lei do Sistema Nacional de Unidades de Conservação como modalidades privilegiadas de territórios de uso sustentável, e ao se adequarem às

\footnotetext{
9 Recentemente, foi lançado no estado o Programa Bolsa Floresta, na sequência do programa federal Bolsa Família, para beneficiar e valorizar famílias ribeirinhas que vivam de atividades sustentáveis e estejam envolvidas em projetos de preservação da natureza, como os moradores de unidades de conservação de uso sustentável. O ex-secretário Virgílio Viana, atual diretor executivo da Fundação Amazonas Sustentável, publicou em 2007 o livro "As florestas e o desenvolvimento sustentável na Amazônia", uma coletânea de textos que traduzem sua trajetória e seus projetos nos últimos anos e que dizem muito sobre a linha de atuação adotada pela SDS desde a sua estada no governo.
}

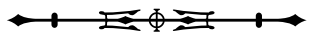


distintas realidades locais, acabaram confluindo em alguns pontos: a RESEX legitimou-se no início e se fez reconhecer junto aos órgãos públicos por meio do que era denominado Plano de Utilização, elaborado pelos próprios seringueiros e aprovado pelo IBAMA; a primeira Reserva de Desenvolvimento Sustentável, para cumprir as exigências dos órgãos governamentais, teve que apresentar e ter aprovado um Plano de Manejo, documento norteador das atividades sobre os usos do espaço e dos recursos, baseado em resultados de pesquisas científicas. Hoje, o documento exigido dos responsáveis pelas RESEX também é um Plano de Manejo com fundamentos técnicos, porém, incorporando o antigo Plano de Utilização elaborado antes por moradores líderes do movimento e assessores. Outra característica que antes marcava a diferença conceitual e política entre os dois modelos diz respeito à questão fundiária e se expressava na exigência, no caso das RESEX, de que fosse feita a desapropriação das áreas privadas existentes. Esta exigência, que é mais flexível nas RDS e que permite, de acordo com o Plano de Manejo, a existência de áreas privadas em seu interior, acaba não sendo cumprida para as RESEX devido as dificuldades que o IBAMA e o ICMBio têm para realizar a regularização fundiária nessas áreas.

De todo modo, o reconhecimento da importância e da legitimidade das territorialidades específicas dos moradores locais em espaços amazônicos transfigurados em Unidades de Conservação de Uso Sustentável faz com que os dois modelos sejam vistos atualmente como conquistas do socioambientalismo brasileiro, apesar das disputas classificatórias e da diversidade de projetos a partir das quais se constituiu o campo ambiental na Amazônia.

Finalmente, ambos os modelos, assim como as demais categorias de unidade de conservação existentes na legislação ambiental brasileira, estão sujeitos à tutela do Estado: há sempre um Conselho Gestor cuja presidência é, por lei, ocupada pelo representante do órgão público responsável, e não por algum representante ou pela liderança dos moradores.
RESEX MÉDIO JURUÁ E RDS UACARI - DISPUTAS

\section{CLASSIFICATÓRIAS QUE PERMANECEM NA} AMAZÔNIA

De fato, estamos lidando com sistemas de classificação do espaço. Os sistemas de classificação que produziram a RESEX Médio Juruá e a RDS Uacari ora estão em disputa, quando do enunciado que dá sustentação à definição dos territórios, como exposto acima, ora operam em complementaridade, quando ambas as reservas são reconhecidas pelo INCRA como projetos especiais de reforma agrária. Embora os discursos classificatórios se apresentem como baseados em critérios técnicos e ecológicos, como no caso da RDS, eles estão, de fato, baseados em critérios sociais porque são parte da vida social. Toda classificação é arbitrária e conjectural (Foucault, 1992; Borges, 2005), deixando transparecer processos sociais complexos e múltiplos interesses. Nesse sentido, não importa tanto se a classificação é correta como realidade, visto que esta é sempre uma invenção (Mendes, 1974; Gondim, 1994). Como sugere Rancière (2005), basta fazer coincidir uma diferença específica com o traçado de uma linha sobre o mapa, constituindo assim territórios imaginários que servem a múltiplos interesses.

A reconceituação da Amazônia na geopolítica mundial e nacional, de fronteira econômica pautada pela exploração intensiva dos recursos naturais para fronteira de preservação da biodiversidade (Becker, 2004), tem levado o Estado, por meio do governo federal e estadual, a redefinir espaços, ora em aliança com os atores locais (moradores das áreas extrativistas, associações, Igreja Católica, movimentos sociais), ora com atores diversos e difusos (pesquisadores, cientistas, ambientalistas, empresários 'verdes'). Esses espaços, antes 'espaços de vida', recortados por critérios primordiais e sociais, têm se convertido, entre outras modalidades, em Reservas Extrativistas e Reservas de Desenvolvimento Sustentável, como as que ora observamos no médio rio Juruá. Os critérios ecológicos, aliados aos interesses das populações locais, tornam-se agora os definidores dos limites e das possibilidades das relações nestas áreas. 


\section{POLÍTICAS PÚBLICAS A PARTIR DAS NOVAS TERRITORIALIDADES - A FACE OCULTA DA TUTELA}

Alguns pesquisadores brasileiros, como Souza Lima (1995), já enveredaram por esta aventura, de tentar elucidar o modo como o Estado foi se constituindo ao fortalecer, por meio de seus agentes, a assimetria entre estes e o 'povo', aqueles a quem deve beneficiar. Tal fenômeno, denominado pelo autor de "poder tutelar", estaria na raiz da formação das políticas indigenistas no Brasil, desde o período colonial até a demarcação das terras indígenas nos governos militares.

Poderíamos pensar, com este mesmo autor (Souza Lima e Barroso-Hoffmann, 2002), em um momento mais recente, no qual a nova configuração do país e a emergência de novas preocupações, como o ambientalismo, e de novos atores, como os 'seringueiros', 'ribeirinhos' e 'extrativistas', em diferentes alianças com as agências governamentais, que culminaram com a 'invenção' das Unidades de Conservação de Uso Sustentável, tais como RESEX e RDS, que estaríamos agora tratando de relações para "além da tutela". Será mesmo?

Em um estudo bem anterior ao de Souza Lima, Oliveira Filho (1988), ao analisar a relação do Serviço de Proteção ao Índio (SPI) e o povo Ticuna na região do alto rio Solimões, no Amazonas, percebeu que a tutela do Estado não pode ser compreendida apenas pela relação de dominação entre os agentes públicos e as populações das áreas protegidas. A relação de tutela apresenta certa complexidade e se sustenta por meio de um paradoxo ideológico. Se, por um lado, ela implica a dominação, por vezes velada do tutor sobre o tutelado, por outro, ela pressupõe, como toda relação de dominação (Simmel, 1983; Weber, 1992), a aceitação, por parte do tutelado, das normas e dos padrões estabelecidos. A interação entre o Estado, as populações das áreas e as demais instituições locais de assessoria à organização destas populações, como a Igreja Católica e o MEB, no caso em questão, abre um leque de possibilidades, cujo padrão de legalidade decorrente torna-se contingente, condicionado por fatores de ordem histórica e cultural.
O fato é que o processo de reconhecimento e legitimação da permanência de uma população humana em ambiente a ser conservado implica sempre alguma forma de enquadramento dessa população, seja pelo governo estadual ou federal, não importando a agência governamental que conduz os processos. Uma das formas pelas quais a legislação que rege a matéria - a Lei do Sistema Nacional de Unidades de Conservação (SNUC) - expressa a tutela é através da exigência de que a presidência do Conselho Gestor das áreas ambientalmente protegidas seja exercida pelo órgão gestor, antes IBAMA, agora ICMBio, no caso das áreas federais, ou pela SDS (especificamente o CEUC), no caso das estaduais. Já as representações das comunidades compõem o referido Conselho no mesmo nível das demais agências governamentais e não governamentais.

Outra evidência de que ainda estamos tratando de tutela, e de modo especial aquela que se abriga sob os cânones da ciência moderna, é o fato de que a legislação exige como documento norteador das reservas a elaboração de Planos de Manejo (PM). Estes são instrumentos de caráter técnico, semelhantes aos previstos para as áreas de proteção integral, como os Parques e as Reservas Ecológicas. $O$ documento antes elaborado pelas comunidades residentes nas áreas, os Planos de Utilização, acabam compondo apenas parte dos Planos de Manejo. Os PM impõem certos conceitos e colocam restrições de uso dos recursos, desconstituindo, de certa forma, os conhecimentos locais, por mais que estes Planos tragam no discurso o emblema do 'caráter participativo'. Dessa forma, poderíamos dizer que os moradores não vivem nesses territórios para além da tutela, mas sim, aprendendo a lidar com sua face oculta.

Podemos perceber, assim, quão complexos e imprevisíveis são tais processos classificatórios, que, como sugere Rancière (2005), promovem uma geografia simbólica dentro de uma política imaginária, recortando os espaços de vida e produzindo territórios que podem conter tanto os elementos da mudança quanto os da reprodução de tudo aquilo que se quer transformar. 


\section{REFERÊNCIAS}

ALLEGRETTI, Mary. A construção social de políticas ambientais, Chico Mendes e o movimento dos seringueiros. 2002. Tese (Doutorado em Desenvolvimento Sustentável) - Universidade de Brasilia, Brasilia, 2002.

ALMEIDA, Alfredo Wagner Berno. Terras de quilombo, terras indígenas, "babaçuais livres", "castanhais do povo", faxinais e fundos de pasto: terras tradicionalmente ocupadas. 2. ed. Manaus: PGSCA-UFAM, 2008.

ALMEIDA, Mauro William Barbosa. Direitos à floresta e ambientalismo: seringueiros e suas lutas. Revista Brasileira de Ciências Sociais, v. 19, n. 55, p. 33-53, 2004.

ALMEIDA, Mauro William Barbosa. Le Statut de la terre et les reserves extrativistes. Cahiers du Bresil Contemporain, Paris, Numéro Spécial, p. 169-189, 1995.

ALMEIDA, Mauro William Barbosa. Rubber tappers of the upper Juruá River, Brazil. The making of a Forest peasant economy. 1992. Tese (Doutorado em Social Anthropology) - University of Cambridge, Cambridge, 1992.

ALPHANDERY, Pierre; BERGUES, Martine. Territoires en questions: pratiques des lieux, usages d'un mot. Ethnologie française, v. 34, n. 1, p. 5-12, 2004.

AYRES, José Márcio. As matas de várzea do Mamirauá. Brasília: MCT-CNPq/PTU; Belém: Sociedade Civil Mamirauá, 1993.

BECKER, Bertha K. Amazônia: geopolítica na virada do III milênio. Rio de Janeiro: Garamond, 2004.

BENATTI, José Heder (Coord.). A questão fundiária e o manejo dos recursos naturais da várzea: análise para a elaboração de novos modelos jurídicos. Manaus: Edições IBAMA/ProVárzea, 2005.

BORGES, Jorge Luis. El idioma analítico de John Wilkins. In: BORGES, Jorge Luis (Ed.). Otras Inquisiciones. Buenos Aires: Emecê, 2005[1960]. p. 149-156.

BOURDIEU, Pierre. Coisas Ditas. São Paulo: Brasiliense, 2004.

BOURDIEU, Pierre. O poder simbólico. Rio de Janeiro: Bertrand Brasil, 1998[1989].

BRITO, Maria Cecília Wey de. Unidades de Conservação: intenções e resultados. São Paulo: Annablume/FAPESP, 2000.

COELHO, Thais Danton. Conflitos, mediação e acordos: os castanheiros do Lago Ayapuá e a RDS Piagaçu-Purus. 2009. Dissertação (Mestrado em Sociologia e Antropologia) - Universidade Federal do Rio de Janeiro, Rio de Janeiro, 2009.

CUNHA, Manoela Carneiro da; ALMEIDA, Mauro Barbosa (Orgs.) Enciclopédia da Floresta. São Paulo: Companhia das Letras, 2002.

DAVIS, Shelton. As Vítimas do Milagre. Rio de Janeiro: Zahar, 1978.
DERICKX, João. Reserva Extrativista, mais vida neste chão. Belém: Meridional, 2007.

DERICKX, João. No coração da Amazônia: Juruá, o rio que chora. Petrópolis: Vozes, 1992.

ESTERCI, Neide. Campesinato e Igreja na Fronteira - o sentido da lei e a força da aliança. In: FERNANDES, Bernardo M.; MEDEIROS, Leonilde S.; PAULILO, Maria Ignez (Orgs.). Lutas camponesas contemporâneas: condições, dilemas e conquistas. São Paulo: Ed. UNESP; Brasilia: NEAD/ MDA, 2009. p. 223-244.

ESTERCI, Neide. Conflitos ambientais e processos classificatórios na Amazônia brasileira. Boletim Rede Amazônia: diversidade sociocultural e políticas ambientais, v. 1, n. 1, p. 51-62, 2002

ESTERCI, Neide. O conflito no Araguaia. Peões e posseiros contra a grande empresa. Petrópolis: Vozes, 1987.

FRANCO, Mariana Ciavatta Pantoja. Os Milton - Cem anos de história nos seringais. 2. ed. Rio Branco: Editora da Universidade Federal do Acre, 2008

FOSTER, George. What is a Peasant? In: POTTER, Jack M.; DIAZ, May N.; FOSTER, George M. (Eds.). Peasant Society: a Reader. Boston: Little Brown, 1967. p. 2-14

FOUCAULT, Michel. As palavras e as coisas: uma arqueologia das ciências humanas. São Paulo: Martins Fontes, 1992[1966].

GONÇALVES, Carlos Walter Porto. Geografia Política e Desenvolvimento Sustentável. Terra Livre, São Paulo, n. 11-12, p. 9-76, 1996.

GONDIM, Neide. A invenção da Amazônia. São Paulo: Marco Zero, 1994

GUSFIELD, Joseph. The social construction of community: concepts as existencial types. In: GUSFIELD, Joseph R. Commmunity, a critical response. New York: Harper \& Row Pub., 1975. p. 23-50.

HEREDIA, Beatriz; GARCIAJR., Afrânio. Trabalho familiar e campesinato. América Latina, v. 14, n. 1-2, p. 10-20, 1971.

LEITE LOPES, José Sérgio. Sobre processos de "ambientalização" dos conflitos e sobre dilemas da participação. Horizontes Antropológicos, v. 12, n. 25, p. 31-64, 2006.

LEITE LOPES, José Sérgio. A ambientalização dos conflitos em Volta Redonda. In: ACSELRAD, H. (Org.). Conflitos ambientais no Brasil. Rio de Janeiro: Relume Dumará, 2004. p. 217-244.

LIMA, Deborah de Magalhães (Org.). Diversidade socioambiental nas várzeas dos Rios Amazonas e Solimões: perspectivas para o desenvolvimento da sustentabilidade. Manaus: IBAMA/Pró-Várzea, 2005.

LIMA, Deborah de Magalhães. Ribeirinhos, pescadores e a construção da sustentabilidade nas várzeas dos Rios Amazonas e Solimões. Boletim Rede Amazônia, v. 3, n. 1, p. 57-66, 2004. 
LIMA, Deborah de Magalhães. Equidade, Desenvolvimento Sustentável e Preservação da Biodiversidade: algumas questões sobre a parceria ecológica na Amazônia. In: CASTRO, Edna; PINTON, Florence (Eds.). Faces do Trópico Úmido: conceitos e questões sobre desenvolvimento e meio ambiente. Belém: Cejup, 1997. p. 285-314.

LIMA, Deborah de Magalhães. A implantação de uma unidade de conservação em áreas de várzea - a experiência do Mamirauá. In: D'INCAO, M. A.; SILVEIRA, I. M. (Orgs.). A Amazônia e a crise da modernização. Belém: Museu Paraense Emílio Goeldi/MCT, 1994. p. 403-409

LITTLE, Paul. Territórios sociais e povos tradicionais no Brasil: por uma antropologia da territorialidade. Brasília: UnB, 2002.

MARTINS, José de Souza. O poder do atraso. São Paulo: Hucitec, 1994.

MARTINS, José de Souza. A chegada do estranho. São Paulo: Hucitec, 1993.

MEDEIROS, Leonilde Sérvolo de. História dos movimentos sociais no campo. Rio de Janeiro: FASE, 1989.

MENDES, Armando Dias. A invenção da Amazônia. Belém: EDUFPA, 1974.

MOURA, Edila Arnaud Ferreira. Práticas socioambientais na Reserva de Desenvolvimento Sustentável Mamirauá, Estado do Amazonas, Brasil. 2007. Tese (Doutorado em Desenvolvimento do Trópico Úmido/NAEA) - Universidade Federal do Pará, Belém, 2007.

MOVIMENTO EDUCAÇÃO DE BASE (MEB). Departamento de Carauari. Memorial Institucional do MEB. Relatório. Amazonas, 2003.

OLIVEIRA FILHO, João Pacheco de. Uma etnologia dos "índios misturados": situação colonial, territorialização e fluxos culturais. In: OLIVEIRA FILHO, João Pacheco de (Ed.). A viagem da volta: etnicidade, política e reelaboração cultural no Nordeste indígena. Rio de Janeiro: Contra-Capa, 1999. p. 13-39.

OLIVEIRA FILHO, João Pacheco de. "O nosso governo": os Ticuna e o regime tutelar. São Paulo: Marco Zero; Brasilia: MCT/CNPq, 1988.

PACHECO, Maria Emília. Entrevista. Proposta, Rio de Janeiro, v. 29, n. 107/108, dez.-maio 2005/2006.

QUEIROZ, L. Helder. A Reserva de Desenvolvimento Sustentável Mamirauá. Estudos Avançados, São Paulo, v. 19, n. 54, p. 183203, 2005.

QUEIROZ, Maria Isaura Pereira. O Campesinato Brasileiro. Rio de Janeiro: Vozes, 1976.
RANCIĖRE, Jacques. Borges à Sarajevo. In: RANCIÈRE, Jacques. Chroniques dês temps consensuels. Paris: La Libraire du XXI Siècle/Seuil, 2005[1996]. p. 15-19.

REIS, Marise. Arengas \& Picicas: as reações populares à implantação da RDSM e ao manejo sustentável e participativo dos recursos naturais. Belém: IDSM/MCT, 2005.

RICARDO, Fany (Org.). Terras Indígenas e Unidades de Conservação da Natureza - o desafio das sobreposições. São Paulo: Instituto Socioambiental, 2004.

SCHWEICKARDT, Kátia H. S. C. As diferentes faces do Estado na Amazônia: etnografia dos processos de criação e implantação da RESEX Médio Juruá e da RDS Uacari no médio Rio Juruá. 2010. Tese (Doutorado em Sociologia e Antropologia) - Universidade Federal do Rio de Janeiro, Rio de Janeiro, 2010.

SCHWEICKARDT, Kátia H. S. C. Um olhar sobre a produção do espaço na Amazônia: os encontros e desencontros entre a política de reforma agrária e a política ambiental no Estado do Amazonas. 2001. Dissertação (Mestrado em Sociedade e Cultura na Amazônia) - Universidade Federal do Amazonas, Manaus, 2001.

SIMMEL, Georg. Superordenação e Subordinação - Introdução. In: MORAES FILHO, Evaristo (Org.). Simmel. São Paulo: Ática, 1983. p. 7-44.

SOUZA LIMA, Antônio Carlos. Um grande cerco de paz. Petrópolis: Vozes, 1995.

SOUZA LIMA, Antônio Carlos; BARROSO-HOFFMANN, Maria (Orgs.). Além da tutela: bases para uma nova política indigenista III. Rio de Janeiro: Contra-Capa Livraria, 2002.

TAVARES-DOS-SANTOS, José Vicente; RUSCHEINSKY, A. A nova questão agrária: luta social e cultural. In: RUCHEINSKY, A. (Org.). Terra e política: a luta social do MST pela Reforma Agrária no Sul do país. Rio Grande: FURG, 2000. p. 7-9.

VIANA, Virgílio M. As florestas e o desenvolvimento sustentável na Amazônia. 2. ed. Manaus: Editora Valer, 2007.

WEBER, Max. Economia y Sociedad: esbozo de sociología comprensiva. México: Fondo de Cultura Económica, 1992.

WOLF, Eric. Antropologia e poder. Brasília: EDUnB; São Paulo: Imprensa Oficial do Estado de São Paulo; Campinas: Editora da UNICAMP, 2003.

WOLF, Eric. Una tipología del campesinado latinoamericano. Buenos Aires: Nueva Vision, 1977. p. 17-64. 